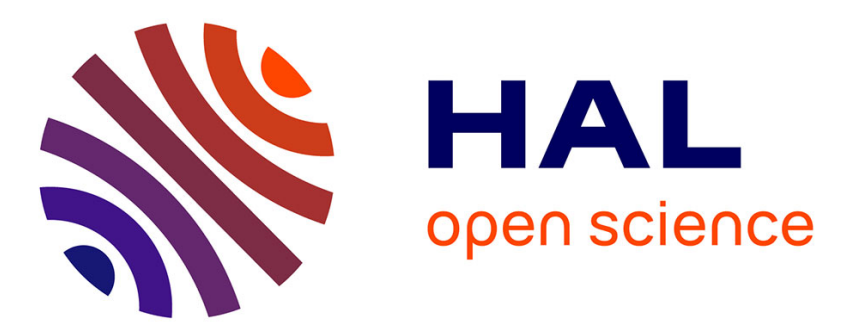

\title{
A Method and a Tool based on a Conceptual Graph for Information Systems Engineering Processes
}

Charlotte Hug, Agnès Front, Dominique Rieu

\section{To cite this version:}

Charlotte Hug, Agnès Front, Dominique Rieu. A Method and a Tool based on a Conceptual Graph for Information Systems Engineering Processes. Fifth International Conference on Evaluation of Novel Approaches to Software Engineering, Jul 2010, Athens, Greece. pp.58-67, 10.1007/978-3-642-233913_7. hal-00671907

\section{HAL Id: hal-00671907 https://hal.science/hal-00671907}

Submitted on 19 Feb 2012

HAL is a multi-disciplinary open access archive for the deposit and dissemination of scientific research documents, whether they are published or not. The documents may come from teaching and research institutions in France or abroad, or from public or private research centers.
L'archive ouverte pluridisciplinaire HAL, est destinée au dépôt et à la diffusion de documents scientifiques de niveau recherche, publiés ou non, émanant des établissements d'enseignement et de recherche français ou étrangers, des laboratoires publics ou privés. 


\title{
A METHOD AND A TOOL BASED ON A CONCEPTUAL GRAPH FOR INFORMATION SYSTEMS ENGINEERING PROCESSES
}

\author{
Charlotte Hug, Agnès Front, Dominique Rieu \\ LIG - Sigma Team - Grenoble University, 220 rue de la Chimie - BP 53, 38041 Grenoble Cedex 9, France \\ \{Charlotte.Hug, Agnes.Front, Dominique.Rieu\}@imag.fr
}

\begin{abstract}
Process engineering, information systems engineering, metamodelling, graph, tool.
In order to build information systems, project managers concentrate on the system to produce but also on the engineering process. Each process is necessarily different for each situation as it depends on the targeted information system. Process modelling is an important step towards information systems quality. Nowadays, method engineers are faced to a lot of different process models; however, they need to adapt them to the organization specificities which is hard to achieve. We propose a method allowing method engineers to build process metamodels to instantiate the process models that meet the actual organizations constraints and specificities. Our method consists of selecting the concepts needed from a conceptual graph, gathering the current knowledge of metamodelling concepts for information systems engineering processes, and integrating them in a new process metamodel. In this paper, we focus on the concepts selection. We also present ProMISE, a tool that supports our method.
\end{abstract}

\section{INTRODUCTION}

To design and produce information systems, project managers focus on the quality of the deliverables produced all along the project life (analysis models, test procedures, for example); as such, they focus on the quality of their definition, formalization, level of detail and completeness. This highly depends on how method engineers define the processes, as the deliverables are the results of the processes (Humphrey and Kellner, 1989). In order to produce information systems, processes for information systems engineering (ISE) have to be efficient and fitted to the organizations specific constraints.

Many information systems/software engineering processes or methods have been defined. They appeared in the 1970's with the Waterfall model (Royce, 1987), the Spiral Model (Boehm, 1986), then the RUP (Kruchten, 2000) and more recently Agile methods as XP (Beck, 1999) and SCRUM (Schwaber and Beedle, 2001). They are based on different process models: they propose different lifecycles, suggest various activities, specify different kinds of deliverables and assign roles differently. Thus, each method proposes its own way to build information systems: each method is based on a different process metamodel that uses different concepts. Existing process metamodels are hardly adaptable and are defined independently of one another (Hug et al., 2008a, 2008c, 2009). Upon modelling the process models of their organizations, method engineers have to use those already predefined process models or to instantiate process metamodels without adaptation possibility; the resulting models might be partially inadequate to the organizations specificities and constraints and their business activities.

Our method helps method engineers to build their own process metamodels according to their organization specificities and technologies. The method consists of selecting the needed concepts from a conceptual graph and integrating them in a new adapted process metamodel. In this paper, we focus on the concepts selection.

In the next section, we present the conceptual graph, base of our adaptive method to build process metamodels for ISE. We introduce the method in Section 3. Section 4 presents a case study of the Grenoble's University Hospital. Section 5 is devoted to discussion and Section 6 presents ProMISE, a tool that supports our method. Section 7 concludes this paper. 


\section{THE CONCEPTUAL GRAPH}

In this section, we present the base of our approach that is a conceptual graph. It was built from a Process Domain Metamodel and a 3D Space. A study (Hug et al, 2008b, 2009) of the different existing process metamodels (activity oriented (OMG. 2008; OPF; OOSPICE; Australian Standard. 2004; ISO/IEC, 2007) such as SPEM, product oriented (Harel, 1987; OMG, 2009; Humphrey and Kellner, 1989; Finkelstein et al., 1990) such as Statechart and State Machines, decision oriented (Kunz and Rittel, 1970; Potts and Bruns, 1988; Potts, 1989; Jarke et al., 1992) like Ibis and Daida, context oriented (Rolland et al., 1995) such as NATURE and strategy oriented (Rolland et al., 1999 ) like MAP), allowed us to define a Process Domain Metamodel (Hug et al., 2008a, 2008c). It only contains the main classes of existing process metamodels and their defined associations. In order to facilitate the classes' selection of the Process Domain Metamodel, we propose the use of a conceptual graph that allows method engineers to navigate easily between the concepts. The concepts are organised according to a $3 \mathrm{D}$ space.

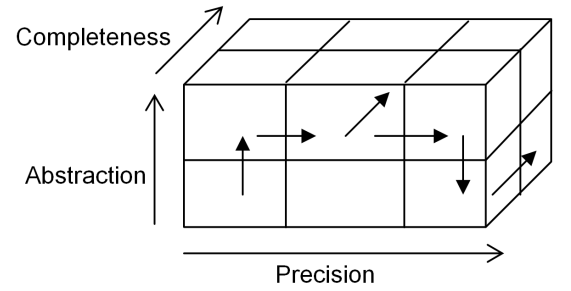

Figure 1: The Completeness - Precision - Abstraction 3D space.

\subsection{The 3D Space}

The 3D space represented in Figure 1 guides method engineers through a methodological frame to build process metamodels for ISE. The three axes (Panet and Letouche, 1994) help method engineers in the selection of the concepts: completeness, precision and abstraction. Completeness is the coverage of the metamodel of one or more points of view (activity, product, decision, context and strategy). Precision is the level of detail of the metamodel. Abstraction is the intentional and/or operational level of concern of the metamodel. The intentional level represents the objectives of the ISE process while the operational level represents the actions required to concretize these objectives. Method engineers will build their process metamodels depending on these three axes: each engineering activity on the Process Metamodel Under Construction (PMUC) has for objective to: extend the PMUC that corresponds to the completeness axis, precise the PMUC that corresponds to the precision axis or abstract (inv. concretize) the PMUC that corresponds to the abstraction axis.

\subsection{The Conceptual Graph}

The conceptual graph (Figure 2) is the base of our method. It organises the recognized concepts for ISE process metamodelling, representing the actual knowledge base of the domain. The purpose of such conceptual graph is to guide method engineers in the Completeness - Precision - Abstraction 3D space while selecting the concepts they need to represent in their metamodels. The conceptual graph defines the set of possibilities: it restrains method engineers in the selection and the use of the defined concepts only, in order to maintain the consistency of the PMUC.

\subsubsection{The Concepts}

The concepts of the conceptual graph are used in ISE processes and are usually represented in process metamodels. The concepts of the graph represent two types of elements:

- Classes that represent the main concepts (concepts in bold in Figure 2) defined in the Process Domain Metamodel and are linked to each other by the completeness and abstraction relations. Those concepts are Work Unit, Condition and Role (activity point of view) (OMG. 2008; OPF; OOSPICE; Australian Standard. 2004; ISO/IEC, 2007), Work Product (product point of view) (Harel, 1987; OMG, 2009; Humphrey and Kellner, 1989; Finkelstein et al., 1990), Issue, Alternative, Argument (decision point of view) (Kunz and Rittel, 1970; Potts and Bruns, 1988; Potts, 1989; Jarke et al., 1992), Situation, Context, Intention (context point of view) (Rolland et al., 1995) and Strategy (strategy point of view) (Rolland et al., 1999). Figure 3 presents a close-up on a few of those. A Work Unit represents an action that is executed during the ISE process. A Work Product is something that is produced, used or modified during the ISE process and a Role is someone/thing that carries out an action during the ISE process. A Strategy represents how an intention is achieved. 


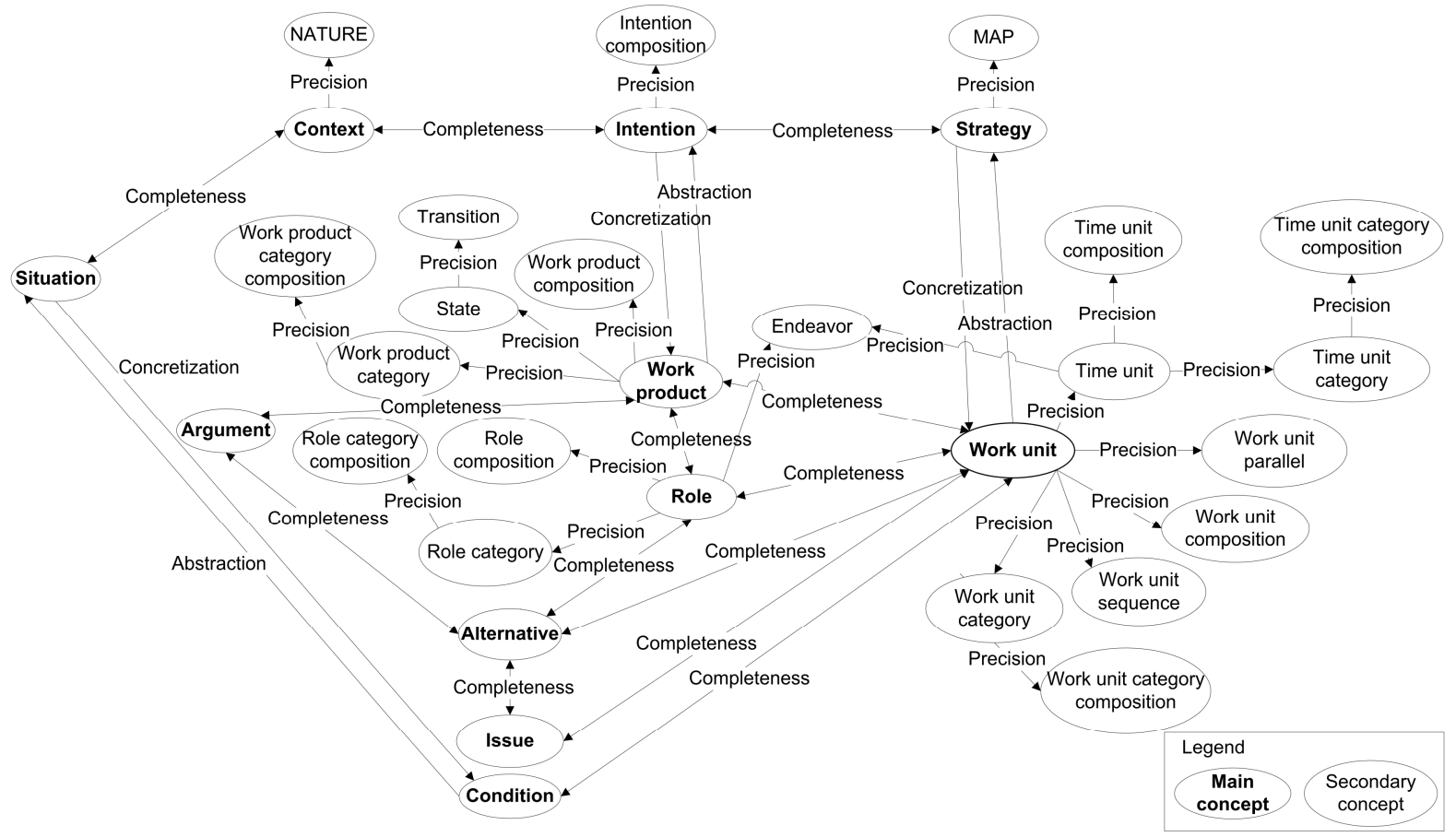

Figure 2: The conceptual graph.

- Classes that decompose the previous classes, linked by the precision relation (secondary concepts). For example, in Figure 3, the Work Unit Category concept refines the Work Unit concept to express the fact that there are different categories of work unit, as activity or task for example. The Work Unit Composition concept refines the Work Unit concept to represent a Work Unit class with a reflexive composition, to express that the "Design components" activity is composed of the tasks "Class design" and "Subsystem design" (Kruchten, 2000), for example.

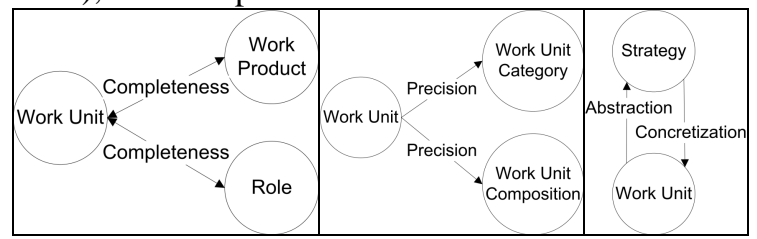

Figure 3: Examples of the Completeness, Precision and Abstraction relations.

\subsubsection{The Relations}

The relations represent conceptual links between concepts in the Completeness - Precision Abstraction 3D space as presented in section 2.1.

The completeness relation links one concept to another that extends it. This relation is symmetric, non-transitive and non-reflexive. For example, in Figure 3 (on the left), the Work Unit concept can be completed by the Work Product and Role concepts. As the Work Product concept can also be completed by the Work Unit concept (symmetry), the represented link is bidirectional.

The precision relation specifies that a concept can be refined by another concept. Such relation is non-symmetric, non-reflexive and non-transitive. For example, the Work Unit concept can be refined using the Work Unit Category or Work Unit Composition concepts (but the Work Unit concept does not refine the Work Unit Category concept non symmetry) (cf. Figure 3 in the centre).

The abstraction relation specifies that one concept can be abstracted by another concept; it is non-symmetric, non-reflexive and non-transitive. For example, the Work Unit concept is abstracted by the Strategy concept (cf. Figure 3 on the right). The inverse relation of Abstraction is Concretization. We can say that the Work Unit concept is the concretization of the Strategy concept.

On the one hand, the relations help method engineers selecting the concepts in the conceptual graph and on the other hand, they assure the coherency of the selected concepts. For example, the Work Unit Category Composition concept can not be selected before the Work Unit Category concept has been selected (see Figure 2). The consistency of the process metamodels produced is then ensured, as the conceptual graph was designed in such a way as the concepts were coherently linked to each others. 


\subsubsection{Example}

The conceptual graph in the Completeness Precision - Abstraction 3D space is dynamically built: the perspective evolves depending on the node the method engineer is considering. Figure 4 shows a part of the 3D perspective that method engineers would see from the Work Unit concept: if they want to extend their PMUC, it will lead to the Work Product and Role concepts thanks to the completeness relation defined in the conceptual graph. If they want to precise their PMUC, it will lead to the Work Unit Category and Work Unit Composition concepts, using the precision relation and if they want to abstract it, it will lead to the Strategy concept thanks to the abstraction relation.

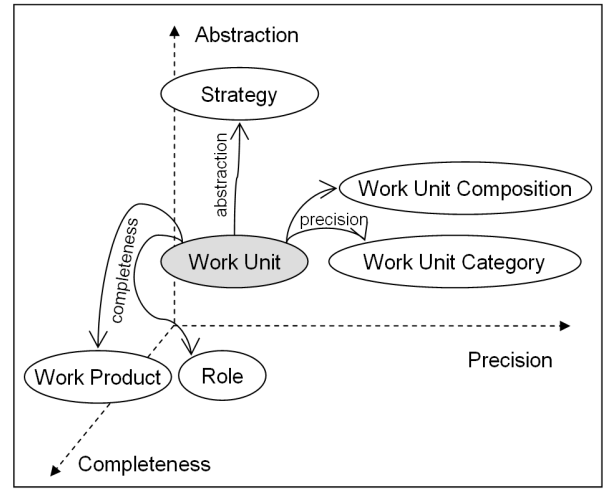

Figure 4: Part of the perspective from the Work Unit concept in the conceptual graph.

We now describe the method that uses the conceptual graph to build process metamodels for ISE.

\section{THE METHOD}

In this section, we present the method based on the conceptual graph for building process metamodels for ISE. The two-step method consists of: (i) concepts selection within the conceptual graph, (ii) concepts integration in the PMUC, according to the Process Domain Metamodel. These two steps are iterated until method engineers obtain the complete process metamodel they need. In this paper, we focus on the description of concepts selection. Figure 5 presents the method by an activity diagram; it uses the conceptual graph described in Figure 2.

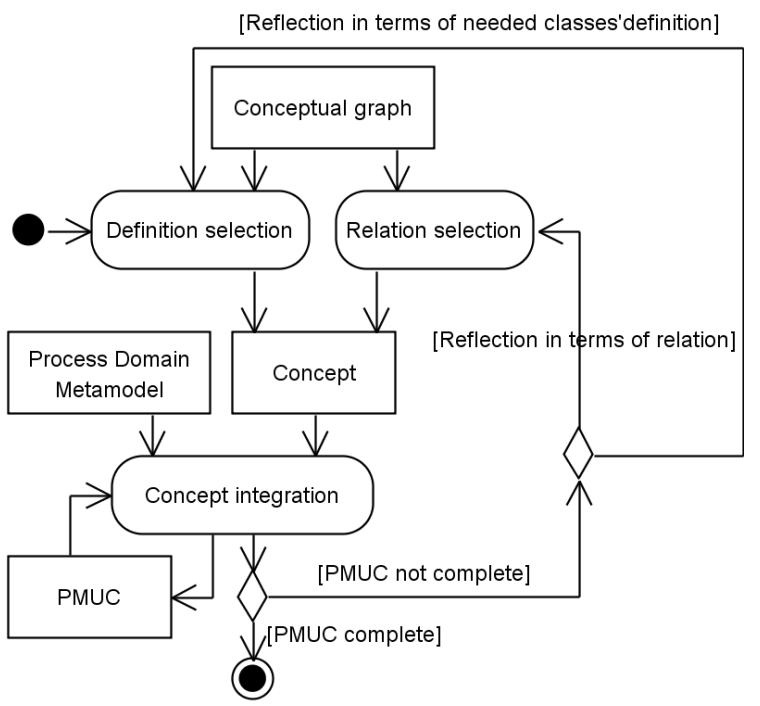

Figure 5: The method represented as an activity diagram.

The first activity of the process is Definition selection that will lead to get a Concept. A definition is composed of a short description, synonyms of the concept and examples (see Table 1). It enables method engineers to select definitions corresponding to their needs. Each definition is associated to a concept appearing as a node in the conceptual graph.

Table 1: Some definitions examples.

\begin{tabular}{|c|c|c|}
\hline Description & $\begin{array}{c}\text { Synonyms, } \\
\text { AKA, examples }\end{array}$ & Concept \\
\hline $\begin{array}{c}\text { Concept that represents how } \\
\text { an intention is achieved }\end{array}$ & $\begin{array}{c}\text { Tactics, } \\
\text { approach, } \\
\text { manner }\end{array}$ & Strategy \\
\hline Objective of the ISE process & Goal & Intention \\
\hline $\begin{array}{c}\text { Task that is executed during } \\
\text { the ISE process }\end{array}$ & $\begin{array}{c}\text { Activity, task, } \\
\text { work definition }\end{array}$ & Work Unit \\
\hline $\begin{array}{c}\text { Work Unit that is composed } \\
\text { of other work units }\end{array}$ & $\begin{array}{c}\text { Activity } \\
\text { composed of } \\
\text { tasks }\end{array}$ & $\begin{array}{c}\text { Work Unit } \\
\text { composition }\end{array}$ \\
\hline $\begin{array}{c}\text { Something that is produced, } \\
\text { used or modified by a work } \\
\text { unit during the ISE process }\end{array}$ & $\begin{array}{c}\text { Product, } \\
\text { document, } \\
\text { model, program }\end{array}$ & Work Product \\
\hline $\begin{array}{c}\text { Someone/thing that carries } \\
\text { out a work unit during the } \\
\text { ISE process }\end{array}$ & $\begin{array}{c}\text { Actor, } \\
\text { developer, } \\
\text { analyst, system }\end{array}$ & Role \\
\hline
\end{tabular}

Then, the corresponding concept is integrated in the PMUC that is updated during the Concept integration activity, based on the Process Domain Metamodel. The integration activity is rather complex: it has to take into account the different types of concepts (main and secondary) and the assembly of the classes into the PMUC. The main concepts of the Conceptual Graph correspond to 
classes in the Process Domain Metamodel. The secondary concepts correspond to design or business patterns that are applied on the classes. The PMUC is thus built by adding classes and applying patterns. The integration process is described in detail in (Hug, 2009).

Method engineers can then choose either to continue the process or to stop it if the PMUC is complete. If they choose to continue, they may refine the PMUC in terms of concepts attainable through relations with the previously integrated concept (completeness, precision and abstraction relations) or in terms of integration of classes thanks to definitions. The Relation selection consists of selecting one of the relations that starts from the concept just integrated. For example, if the method engineer just integrated the Work Unit concept to his/her PMUC and if he/she wants to extend the PMUC, he/she could select Role, Work product and all the concepts linked through the completeness relation to the Work Unit concept in the conceptual graph. It works in the same way through the precision and abstraction relations.

Table 2 presents a brief example of the construction of a process metamodel. The first step consists of selecting a concept thanks to its definition. Depending on the need of the method engineer at this stage, he/she chooses the definition that corresponds to the Work Unit concept (first loop/Selection). The concept integrated into the PMUC corresponds to the Work Unit class (First loop/Integration). In the second loop, the method engineer might choose to think in terms of relations to extend the PMUC. Thanks to the completeness relation, he/she can select the Work Product concept. The concept is integrated in the PMUC as the Work Product class; the associations between the two classes are also integrated. These relations are issued from the Process Domain Metamodel, but we do not detail this operation here.

Table 2: Example of the two first loops of the construction of a process metamodel.

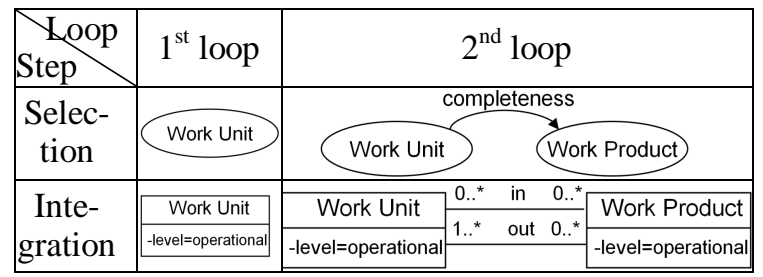

\section{CASE STUDY}

This section describes an extract of a case study of the information system centre of Grenoble's University Hospital (http://www.chu-grenoble.fr/). This case study has not a purpose of validating our method but illustrating it. We specifically conducted qualitative evaluations to validate the method (Hug et al., 2010).

\subsection{Requirements}

The information system centre (ISC) manages approximately forty different applications that need to be regularly updated to meet new users' requirements (medical assistants, hospital doctors and administration staff).

The ISC managers want to model the ISE processes to achieve a more rigorous project management, defining a unified and optimal way to manage projects regardless of the development team. They also want to collect and reuse knowledge for a more efficient production in terms of resources and time use and therefore costs. A method engineer is in charge of the study of the ISE processes and their modelling. The method engineer in this case study is one of the project managers of the ISC.

We have worked with this project manager who determined the various aspects of the ISE processes (this case study only presents an extract of the problem):

- A part of the process is defined in terms of goals and sub-goals; this part is intended primarily for hospital services managers (services are for example the surgical unit, the neurology or the accounting department) who are more interested in the results and impacts of new system functionalities on their service (intentional part),

- The second part of the process is defined by phases, activities and products produced during these activities (operational part).

The problems met by the method engineer are the following: how can he represent these concepts? What are the existing models? Which models meet these requirements? At the present time, these representation choices are made difficult because of the numerous existing process models and metamodels, their lack of mutual complementarity and the complexity to adapt them to specific needs of organizations.

Our method enables the method engineer to model the process metamodel that corresponds to the information system centre ISE processes. The method guides him through the selection of concepts 
he needs to represent and through their assembly in order to create a specific process metamodel including all the concepts at the intentional level concerning the services managers and at the operational level concerning the ISE process it-self.

\subsection{Method Use}

The first step of our method is the selection of a concept by its definition. To select the first concept, the method engineer must select one of the definitions that correspond to the concepts he wants to model. The definition "Goal or objective of the ISE process" corresponds to the part of the process defined in terms of goals. The engineer chooses this definition and the corresponding Intention class is integrated in the new PMUC. The method engineer examines then the relations of the Intention concept in the conceptual graph; the precision relation permits him to select the Intention Composition concept that will allow him to decompose the goals into sub-goals. This concept is integrated in the PMUC as a reflexive composition on the Intention class. Figure 6 presents this part of the path in the conceptual graph and the corresponding PMUC.

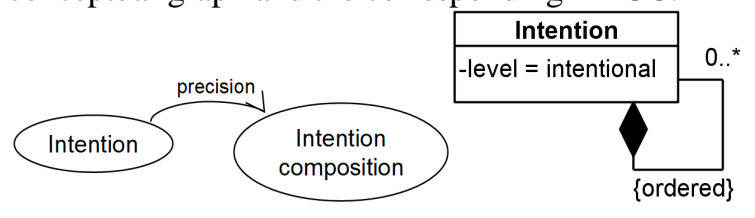

Figure 6: First part of the path in the conceptual graph and the PMUC.

Then, the relation concretization starting from the Intention concept in the conceptual graph allows the method engineer to get the Work Product concept that will represent the products produced during the ISE process. The corresponding class is integrated in the PMUC, as well as the "concretizes" dependency linked to the Intention class.

In order to model the fact that a work product can be composed of other work products (for example, "Functional specifications" is composed of "Simplified requirements" and "Actors diagram"), the method engineer refines the Work Product concept thanks to the Work Product Composition concept. To specify that work products are of different types (for example, "Functional specifications" is a document and "Actor diagram" is a UML diagram), the method engineer refines the Work Product concept by the Work Product Category concept. The Work Product Category class is added into the PMUC. Similarly to what was done with the Work Product, the engineer wants to specify that a document is composed of UML diagrams, texts and graphics. He refines the Work Product Category concept by the Work Product Category Composition concept. Figure 7 presents the corresponding part of the path in the conceptual graph and the corresponding PMUC.

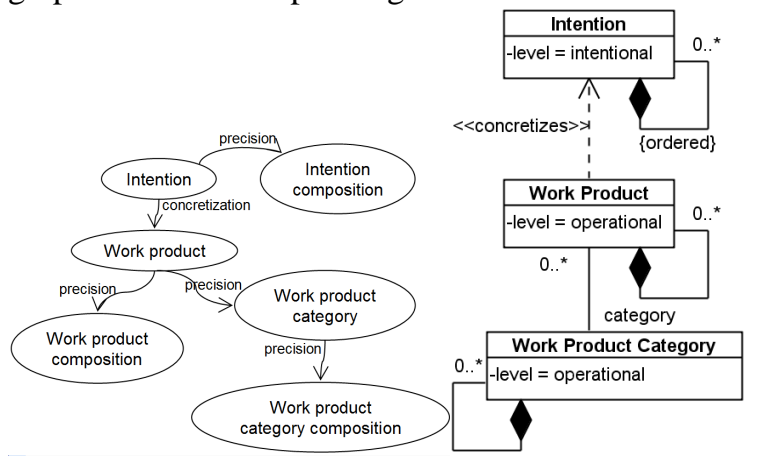

Figure 7: Second part of the path in the conceptual graph and the PMUC.

Thanks to the completeness relation, the method engineer can extend the PMUC with the Work Unit concept to represent activities and steps. The Work Unit class and its associations "In" and "Out" defined in the Process Domain Metamodel are integrated to the PMUC. By using the precision relation, the method engineer can refine the Work Unit concept to represent the sequence and the composition of work units, the work unit categories and the composition of work unit categories. Figure 8 presents the complete path carried out in the conceptual graph.

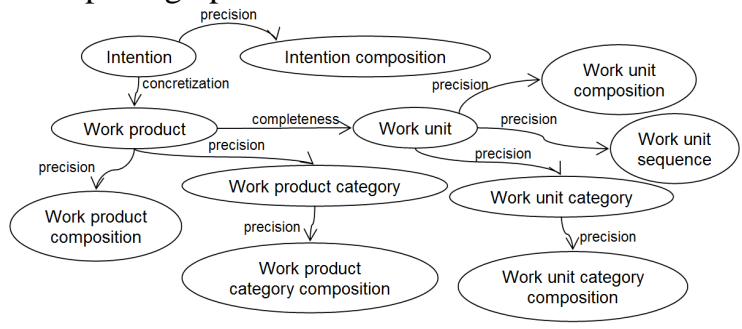

Figure 8: Complete path in the conceptual graph.

Figure 9 presents the final process metamodel obtained thanks to the method. It models the classes defined in the requirements and the associations between them. The link between the classes of intentional and operational level is represented by the dependency link stereotyped as "concretizes". The abstraction level of each class is represented as an attribute level. 


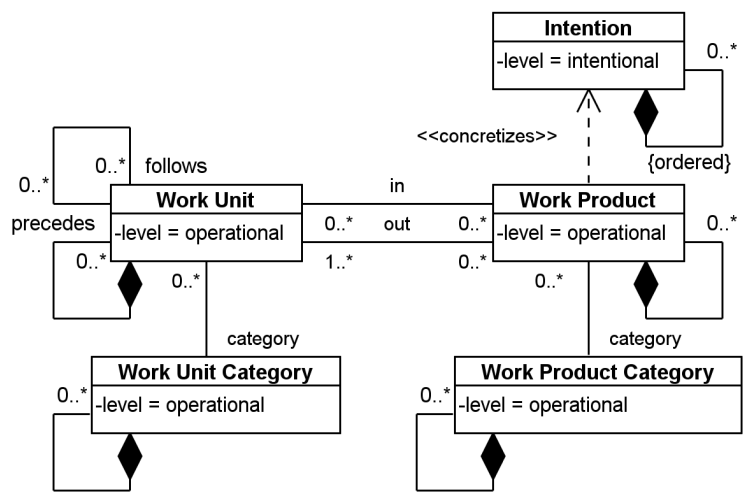

Figure 9: The final process metamodel.

The method engineer can then instantiate the metamodel to represent the various ISE process models of the ISC. Figure 10 is a partial instantiation of the final process metamodel to represent the ISE processes.

The method engineer wants to model the intentions and sub-intentions of service managers. One of the intentions of the service managers is to know the level of impact of a new functionality and the changes impacted on the services.

This can be represented as the object "Define the level of impact of the change in the service", instance of the Intention class (see Figure 10). This intention can be decomposed into two subintentions. Service managers want to define the impact of the change in the service organisation and the persons that will be impacted by the change. These estimations will be useful to define the costs of the information systems change, as costs of business process modifications. The operational abstraction level of the process model represents the detail of the "Pre-functional study" activity composed of three steps. First, "Simplified requirements specifications" produces the
"Simplified requirements" work product that is a text. Second, the "Constitution of business terms glossary" step produces a glossary that is a text. Finally, "Actors modelling" produces a UML diagram "Actors diagram". The whole work products produced during the Pre-functional study forms a document called "Functional specifications" (not represented in Figure 10).

The two sub-intentions "Define the impact on the service organization" and "Define the persons who are impacted by the change" are concretized by the "Simplified requirements" and "Actors Diagram" work products.

The process model represented as an object diagram is not easy and quickly understandable. Our method suggests a graphical representation (formalism) depending on the concepts selected in the process metamodel. For example, if concepts of the operational level as work unit and work product are defined in the metamodel, the method will propose to use activity diagrams (OMG, 2009). If intentions and strategies are used, the method will propose the MAP formalism (Rolland et al., 1999), if there are only intentions, the KAOS formalism (Objectiver, 2007) will be proposed.

Figure 11 shows how we can represent the intentions and sub-intentions of the intentional level defined in Figure 10 using the KAOS formalism. The intentions and sub-intentions are represented as parallelograms. The composition is modelled thanks to a circle.

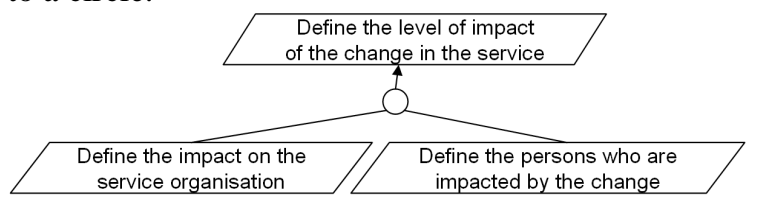

Figure 11: Intentions and sub-intentions in the ISE process of the case study.

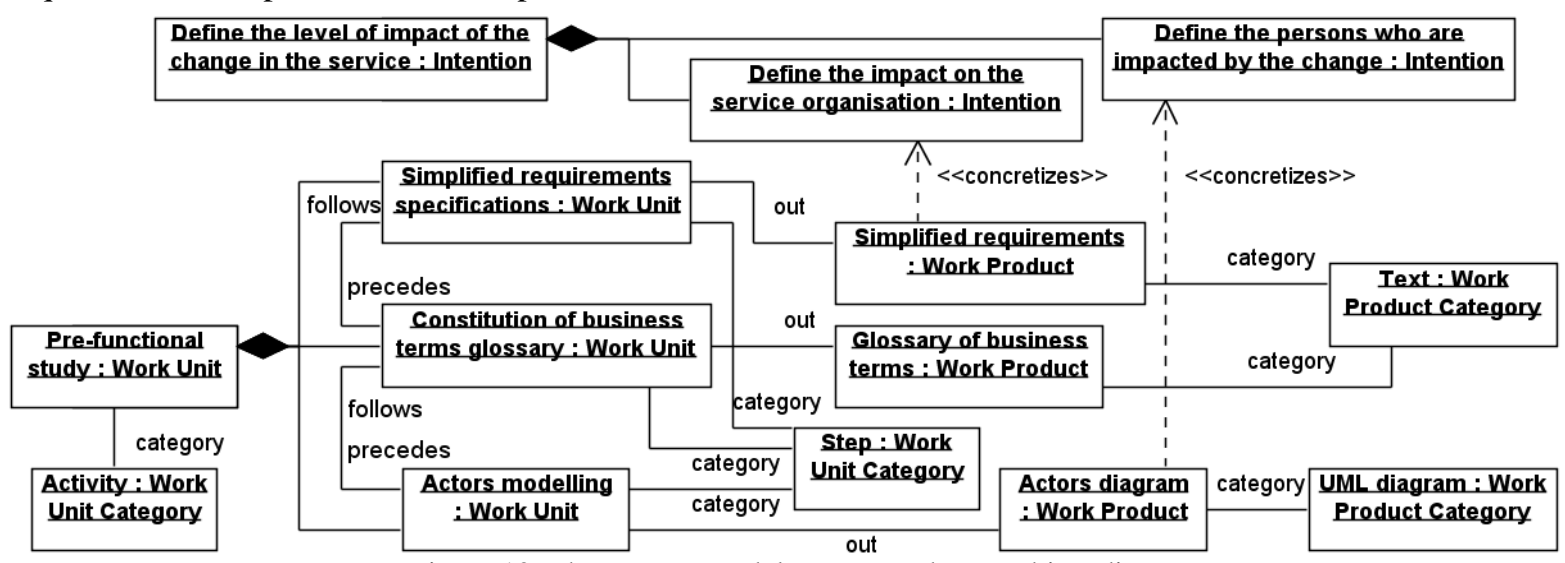

Figure 10: The process model represented as an object diagram. 
Figure 12 presents the concepts of the operational level defined in Figure 10 as an activity diagram. The activities and steps are represented with rounded rectangles. All the work products are represented by rectangles. Stereotypes are used to specify the category of the work products.

However the "concretizes" dependencies are not shown in the figures, there are defined between the different work products and intentions of the models and method engineer, service managers or project managers can switch from one level to another.

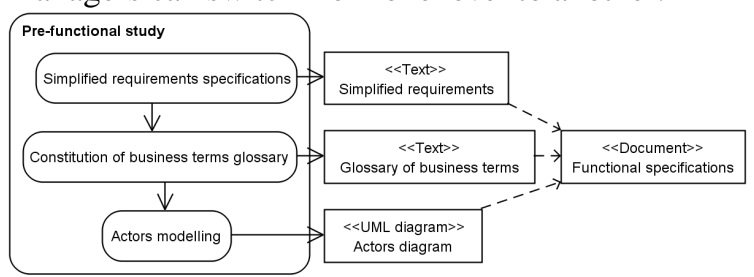

Figure 12: An activity of the ISE process of the case study.

\section{DISCUSSION}

Our proposition offers method engineers to build process metamodels for ISE depending on the needs, the specificities, the context or the situation of the projects or organisations. Our purpose differs from Situational Method Engineering, as it aims at defining information systems development methods by reusing and assembling different existing method fragments (Ralyté and Rolland, 2001), but it is set in the same trend of situational engineering. We may name our domain SPME (Situational Process Metamodelling Engineering).

Let us note that we do not reconsider the existing process metamodels. They all play a part in ISE processes and have their legitimacy. However, they do not define their concepts complementarity in respect to the other process metamodels. Our proposition does not consist of yet another process metamodel, but it proposes a method allowing method engineers to build process metamodels including complementarity between the concepts. Our method uses some part of the existing process metamodels. Therefore, method engineers can reuse knowledge they acquired from their experience in ISE process metamodelling. There lies the real contrast between our proposal and currently available process models, such as RUP (Kruchten, 2000) or SCRUM (Schwaber and Beedle, 2001), process models that are hardly adaptable. Applying these, method engineers must follow them as described and have a little or no mean of customization. Our method, on the other hand, proposes method engineers to instantiate process models according to their needs from process metamodels they have defined themselves but still using widely accepted concepts and formalism of ISE process models.

The existing process metamodels (Hug et al., 2009) are also fixed. They do not allow method engineers to extend them or customize them to add concepts they would need in their process models. Their use is therefore limited as they do not provide all needed concepts. For example, adding the intention concept to the RUP model would be difficult as it is not define in the RUP metamodel. Using it without defining it in the metamodel could lead to misuses and the relations with the other concepts would not be defined.

Finally, new process metamodels as ISO/IEC 24744 (ISO/IEC, 2007) are more flexible and provide more concepts than previous process metamodels thanks to metamodelling mechanisms as the Powertype. However, the strategy, intention and decision concepts are not taken into account here.

To conclude, we can say that our method allows more flexibility, more personalized adaptation and allows building process metamodels with less limitation than the existing one.

\section{PROMISE}

In this section, we present ProMISE (Process Metamodelling for Information Systems Engineering), a tool that supports our method.

\subsection{Technical Architecture}

Figure 13 describes the architecture of ProMISE. The tool has been built using Java. The two main supports of the method, the conceptual graph and the Process Domain Metamodel (Hug et al., 2008a, 2008c, 2009), are defined independently from the tool in XMI files. XMI (OMG. 2007) is a standard format that allows storing UML diagrams as structured text files. The main benefit of having the supports outside the tool is to permit more flexibility and scalability as the guiding will be generated thanks to the conceptual graph file and not the tool it-self. The guiding evolves as the conceptual graph evolves.

Method engineers can interact with a visual conceptual graph, thanks to Prefuse (Prefuse. 2009). Prefuse is a powerful toolkit for creating rich interactive data visualizations, such as graph. 
The Process Metamodel Under Construction, PMUC, is displayed as a UML class diagram using the API UMLJGraph (UMLJGraph. 2005) that allows displaying UML diagrams in Java.

The PMUC can be exported as an XMI file. This allows method engineers to import their process metamodels in any CASE tool, to instantiate them for example.

The imports and exports are done thanks to JDom (JDOM. 2007), a Java API able to read and write both XML and XMI files.

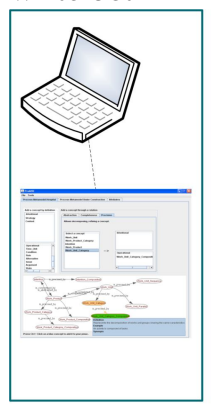

Interface

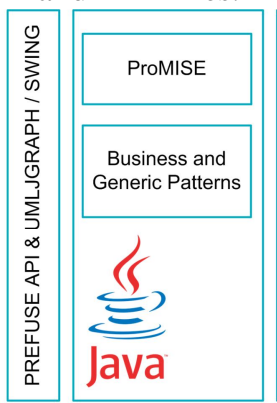

Application

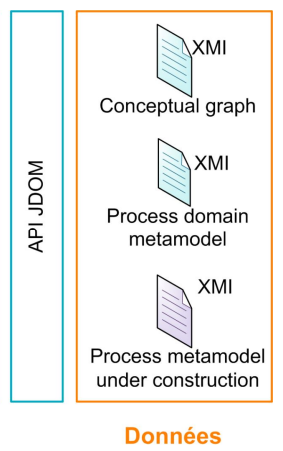

Données
Figure 13: Architecture of the ProMISE tool.

\subsection{General Organisation}

The tool allows method engineers to build process metamodels through the use of the concepts definition and the relations. Figure 14 presents a global view of the interface. It is composed of three tabs:

- The first tab (here called "Process-MetamodelHospital) allows method engineers to build their PMUC for a particular organization or project through the use of the definitions and the relations.

- The second tab, "Process Metamodel Under Construction", allows method engineers to view their PMUC as a UML class diagram.

- The third tab, "Attributes", allows method engineers to add attributes to their PMUC classes, we will not detail this functionality here.

\subsection{Construction of the PMUC}

The first tab that allows the construction of the PMUC is decomposed in two parts:

- The top part of the interface permits to select concepts by definition or by relation. Concepts are displayed according to their abstraction level which facilitates their selection. The definition, examples and synonyms of each concept can be seen by mouse over.
Each relation (completeness, precision, abstraction) is represented by a tab. By selecting one tab, the concepts that can be integrated through the corresponding relation are displayed in the lists. For example, in Figure 14, the Precision tab is selected. Work Unit Category is a concept that can be refined; this allows selecting the Work Unit Category Composition concept.

- The lower part of the interface shows the conceptual graph with the already integrated concepts in the PMUC and the concepts that can be reached by the relations and that can be integrated in the PMUC (Work Unit Category Composition in Figure 14). By selecting a relation tab, the conceptual graph is updated with the concepts that can be integrated.

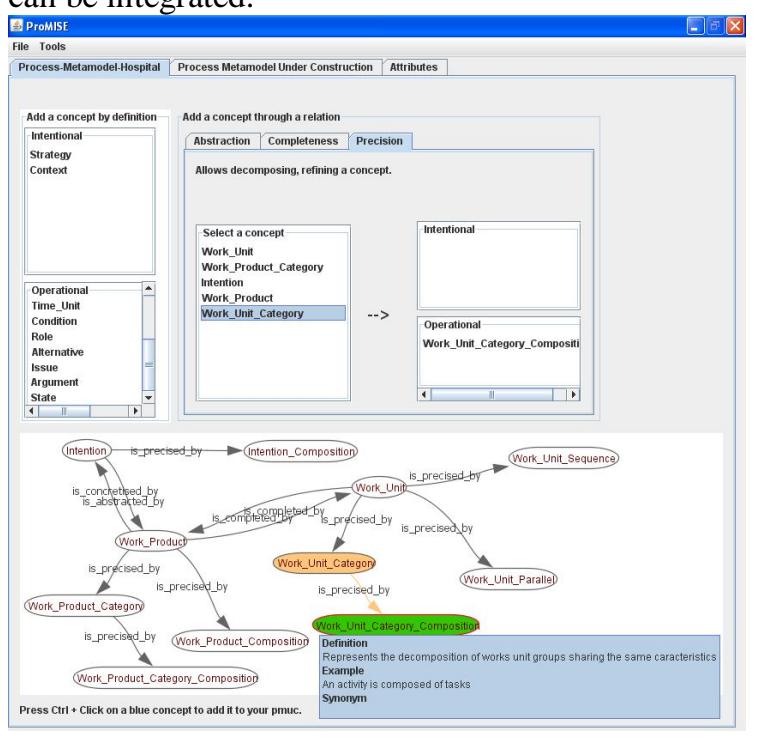

Figure 14: Interface of the ProMISE tool.

\section{CONCLUSION}

In this paper, we present a method that allows method engineers to build process metamodels for ISE. The method is based on two steps: (i) the selection of concepts meeting the specificities and constraints of the projects or organizations, using a conceptual graph to help the concepts selection in a completeness - precision - abstraction 3D space; (ii) the integration of the concepts permits building an adapted process metamodel called PMUC. We present our method as an activity diagram. We have to detail further the integration step, as it is a complex task. 
A tool, ProMISE, has been implemented to allow method engineers to build process metamodels according to our method. Further step is to allow the instantiation of the process metamodels until the monitoring of particular information systems engineering projects.

The Process Domain Metamodel may evolve, with the publication by the community of new process models and metamodels for ISE. The conceptual graph will also evolve, in order to propose method engineers the largest choice of possibilities taking into account the latest evolutions in terms of ISE process metamodelling.

Another part of perspectives concerns the formalism that method engineers should use to represent the process models instantiated from the metamodels produced by this method. It would be useful to guide method engineers in the use of such or such formalism, depending on the concepts selected in their PMUC.

\section{REFERENCES}

Australian Standard. 2004. Standard Metamodel for Software Development Methodologies. AS 4651 2004.

Beck, K. 1999. Extreme Programming Explained: Embrace Change. Addison-Wesley Professional, Longman Publishing Co., Inc. Boston, Massachusetts.

Boehm, B. 1986. A spiral model of software development and enhancement. SIGSOFT Soft. Eng. Notes, vol. 11, $\mathrm{n}^{\circ} 4,14-24$.

Finkelstein, A., Kramer, J., Goedicke, M. 1990. ViewPoint oriented software development. $3^{\text {rd }}$ International Workshop on Software Engineering and Its Applications, 374-384.

Harel, D. 1987. Statecharts: A Visual Formulation for Complex Systems. Science of Computer Programming, vol. 8, n³, 231-274.

Hug, C., Front, A., Rieu, D. 2008a. A Process Engineering Method Based on a Process domain Model and Patterns. MoDISE'08 held in conjunction with CAiSE'08, 126-137.

Hug, C., Front, A., Rieu, D. 2008b. Ingénierie des processus. Une approche à base de patrons. Revue RSTI, série ISI. Vol. 13, n 4 , Hermès, France, 11-34.

Hug, C., Front, A., Rieu, D. 2008c. Process Engineering Method Based on Ontology and Patterns. ICSOFT'08, 29-36.

Hug, C., Front, A., Rieu, D., Henderson-Sellers, B. 2009. A Method to build Information Systems Engineering Process Metamodels. J. Syst. Software, vol. 82, $\mathrm{n}^{\circ} 10$, 1730-1742.

Hug, C., 2009. Méthode, modèles et outil pour la métamodélisation des processus d'ingénierie de systèmes d'information. Joseph Fourier- Grenoble I University, $\mathrm{PhD}$ Thesis.

Hug, C., Mandran, N., Front, A., Rieu, D. 2010. Qualitative Evaluation of a Method for Information Systems Engineering Processes. RCIS'2010.

Humphrey, W. S., Kellner, M. I. 1989. Software process modeling: principles of entity process models. ICSE '89I, ACM, New York, NY, 331-342.

ISO/IEC. 2007. 24744 Software Engineering - Metamodel for Development Methodologies.

Jarke, M., Mylopoulos, J., Schmidt, J.W., Vassiliou, Y. 1992. DAIDA: An Environment for Evolving Information Systems. ACM Trans. on Inf. Sys., vol. $10, \mathrm{n}^{\circ} 1,1-50$.

JDOM. 2007. http://www.jdom.org/

Kruchten, P. 2000. The Rational Unified Process: An Introduction. Addison-Wesley, Longman Publishing, Co., Inc. Boston, Massachusetts.

Kunz, W., Rittel, H.W.J. 1970. Issues as elements of information systems. Working Paper 131, HeidelbergBerkeley.

Objectiver. 2007. A KAOS tutorial. Respect-It.

OMG. 2007. MOF 2.0 / XMI Mapping Specification. Version 2.1.1.

OMG. 2008. Software Process Engineering Meta-Model. Version 2.0.

OMG. 2009. Unified Modeling Language: Superstructure. Version 2.2.

OOSPICE, Software Process Improvement and Capability Determination for Object- Oriented/ ComponentBased Software Development, http://www.oospice.com

Open Process Framework, http://www.opfro.org

Panet, G., Letouche, R. 1994. Merise/2 Modèles et techniques Merise Avancés. Les Editions d'Organisation, Paris.

Potts, C. 1989. A generic model for representing design methods. ICSE'89, IEEE Com. Soc./ ACM Press, 217226.

Potts, C., Bruns, G. 1988. Recording the Reasons for Design Decisions. ICSE'88, IEEE Com. Soc. Press, 418-427.

Prefuse. 2009. http://prefuse.org/

Ralyté J., Rolland, C. 2001. An Assembly Process Model for Method Engineering. CAiSE 2001, LNCS, vol. 2068, 267-283. Springer-Verlag, London.

Rolland, C., Prakash, N., Benjamen, A. 1999. A MultiModel View of Process Modelling. Requirements Engineering, vol. 4, n ${ }^{\circ}$, 169-187.

Rolland, C., Souveyet, C., Moreno, M. 1995. An Approach for defining ways-of-working. Information System Journal, vol. 20, n 4 , 337-359.

Royce, W. W. 1987. Managing the development of large software systems: concepts and techniques. ICSE'87, IEEE Com. Soc. Press, 328-338.

Schwaber, K., Beedle, M. 2001. Agile Software Development with SCRUM. Prentice Hall, Upper Saddle River, New Jersey.

UMLJGraph. 2005. http://umljgraph.sourceforge.net/ 